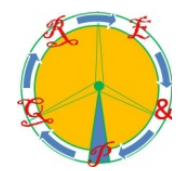

\title{
Frequency Domain Stability Assessment of Photovoltaic Power Generation Systems with Quasi-Z-Source Inverters
}

\author{
L. Sainz ${ }^{1}$ Ll. Monjo ${ }^{2}$ \\ ${ }^{1}$ Department of Electrical Engineering \\ E.T.S.E.I.B., UPC \\ Av. Diagonal 647, 08028 Barcelona (Spain) \\ Phone/Fax number: +0034 93 4011759, e-mail: luis.sainz@upc.edu \\ ${ }^{2}$ Department of Industrial Systems Engineering and Design \\ Universitat Jaume I \\ Av. Vicent Sos Baynat s/n, 12071 Castelló de la Plana, Spain \\ Phone/Fax number: +0034 964 728174, e-mail: Imonjo@uji.es
}

\begin{abstract}
Photovoltaic power generation systems are one of the main renewable power sources, and quasi-Z-source inverters are becoming powerful devices to integrate these systems in $\mathrm{AC}$ grids. However, stability issues due to the damping behaviour of converters must be considered. There are several studies in this direction but instability concerns are not completely solved yet. This paper contributes with a procedure for the stability assessment of photovoltaic power generation systems with quasiZ-source inverters in the frequency domain. The study is based on the small-signal averaged model of the system expressed in the $s$-domain and the stability criterion derived from the frequency characteristics of the state-space matrix. The influence of the photovoltaic power generation system operating point on stability is studied by the proposed procedure. Eigenvalue analysis and PSCAD/EMTDC simulations are also performed to validate the obtained results.
\end{abstract}

Key words. Photovoltaic systems, quasi-Z-source inverters, small-signal model, state-space model, stability

\section{Introduction}

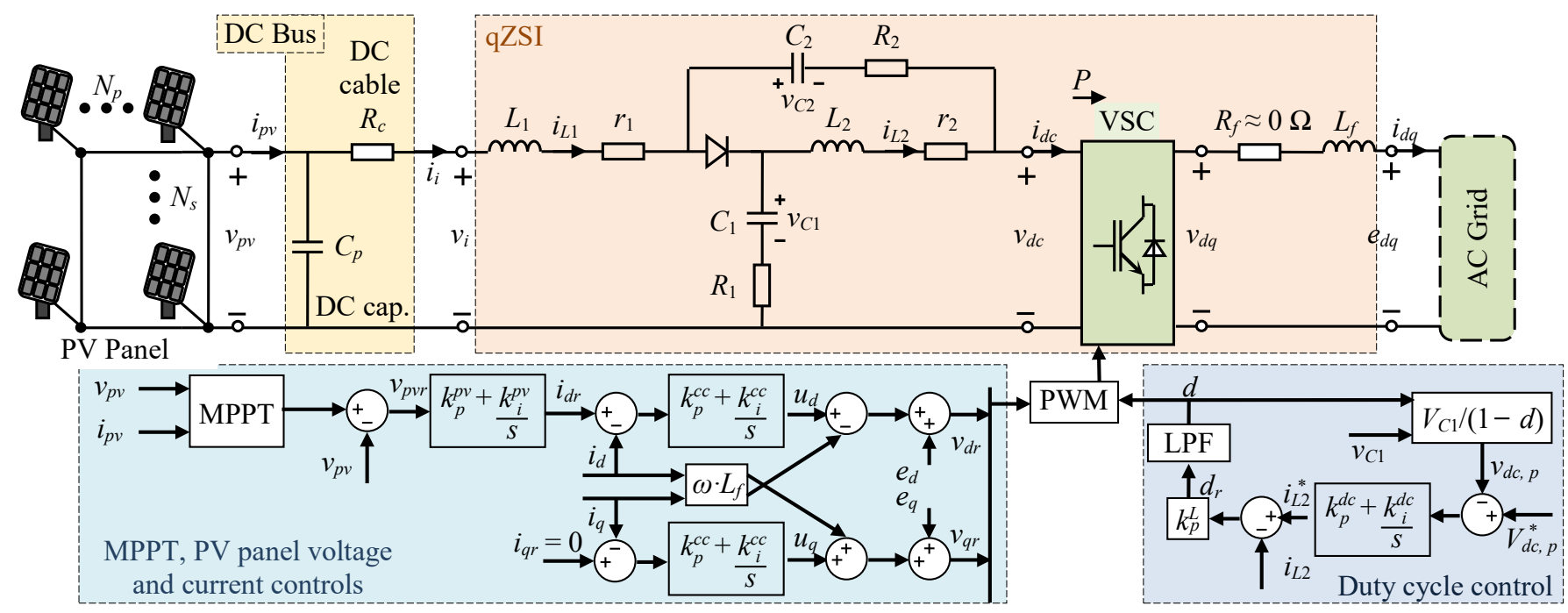

Renewables such as photovoltaic (PV) and wind power generation systems are steadily replacing fossil fuels in power grids [1]-[3]. Broadly speaking, they have single- or two-stage designs, with the most common being the $\mathrm{DC} / \mathrm{DC}$ and $\mathrm{DC} / \mathrm{AC}$ voltage source inverter configuration [4], [5]. However, single-stage configurations based on Z-source inverters are becoming an attractive alternative [5] - [8]. A control method for Z-source cascade multilevel inverter-based single-phase grid-tie PV systems is studied in [5]. An exhaustive comparison of Z-source inverters on their passive components and semiconductors, and an extensive review of these inverters (main topologies, modelling, control, and modulation techniques) are presented in [6] and [7], [8], respectively. Specifically, quasi-Z-source inverters (qZSIs) offer buck-boost DC voltage and energy conversion capabilities in a single step, which improves reliability and efficiency [1], [9] - [12]. Conventional qZSIs are studied in [1], [9], [10], while [11], [12] examine

Fig. 1. Circuit of the qZSI PV power generation system. 
a new qZSI topology which combines the qZSI and the three-level neutral-point-clamped inverter, thus offering the advantages of both topologies.

PV power generation systems often pose a risk of oscillatory instability due to the non-passive behaviour of power electronics in certain operation conditions [13]. State-space eigenvalue analysis and frequency domain criteria are commonly used for examining this phenomenon. Many works investigate stability issues of PV power generation systems with two-stage topologies [3], [14], [15], but few studies deal with qZSI PV power generation system stability. These studies only analyse qZSI dynamics and stability [1], [7]- [10], [16]. The influence of qZSI control on qZSI stability is examined in [1], [9], [10]. An exhaustive study of pole-zero location and impact of parameters on dynamics of several Z-source inverters (including qZSIs)] is conducted in [7], [8]. A stability study is carried out from the small-signal statespace averaged model of the qZSI in [16]. There are only a few studies on dynamics of the complete system [6], [17] - [22]. Most of them focus on the assessment of AC network impedance performance on the DC side [18], [20], [21]. The impact of AC grid on qZSI PV power generation system dynamics is investigated in [6], [17], [19]. PSCAD and Simulink models of qZSI PV power generation systems and a system stability study are presented in [22].

This paper presents an $s$-domain model of qZSI PV power generation systems derived from the small-signal statespace averaged equations in [22] and an approach for system stability assessment based on frequency domain characteristics of the state-space matrix determinant. This frequency domain stability approach has been mainly applied to the analysis of power systems with highpenetration of grid-connected VSCs but it has not yet been used in PV power generation systems. According to this, the main contributions of the paper are

- the presentation of the small-signal state-space averaged equations of all PV power system elements, and subsequent derivation of the $s$-domain model of qZSI PV power generation systems and

- the application of the frequency domain stability criterion based on the state-space matrix determinant to qZSI PV power generation systems.

Other contributions are the study of the impact of the system operating point on stability by using the proposed stability approach, and the validation of the efficacy of this approach by eigenvalue analysis and PSCAD/EMTDC simulation.

\section{Model of qZSI PV Power Systems}

The circuit of qZSI PV power generation systems is shown in Fig. 1. It consists of a DC bus where an $N_{p} \times N_{s}$ (number of PV panels in parallel $\mathrm{x}$ number of PV panels in series) $\mathrm{PV}$ array is connected with a shunt capacitor $C_{p}$ and a DC cable, characterized with a resistance $R_{c}$, to the qZSI, which boosts the output voltage $v_{d c}$ at the VSI terminals. The circuit considers all the main controls. The maximum power point (MPP) tracking (MPPT) control is used to obtain the maximum power from the PV panel. The PV and current control loops ensure power flow from the PV panel to the AC grid. The duty cycle control of the qZSI allows the DC peak voltage to be fixed.
This Section presents the small-signal state-space averaged equations of all PV power system components and controls [22]. These equations yield the model of the qZSI PV power generation system written as

$$
\frac{d \Delta \mathbf{x}}{d t}=\mathbf{A} \Delta \mathbf{x}+\mathbf{B} \Delta \mathbf{u} \quad \Delta \mathbf{y}=\mathbf{C} \Delta \mathbf{x}+\mathbf{E} \Delta \mathbf{u},
$$

where $\Delta \mathbf{x}, \Delta \mathbf{u}$, and $\Delta \mathbf{y}$ are the incremental state, input, and output vectors, respectively, and $\mathbf{A}, \mathbf{B}, \mathbf{C}$ and $\mathbf{E}$ are the coefficient matrices.

From (1), the qZSI PV power generation system outputs can be expressed with respect to the inputs in the $s$ domain as

$$
\begin{aligned}
& \Delta \mathbf{y}(s)= \\
& \left(\mathbf{C}(s \mathbf{I}-\mathbf{A})^{-1} \mathbf{B}+\mathbf{E}\right) \Delta \mathbf{x}(s)=\mathbf{F}(s) \Delta \mathbf{x}(s),
\end{aligned}
$$

where $\mathbf{I}$ is the identity matrix and $\mathbf{F}(\mathrm{s})$ is the transfer function of the qZSI PV power generation system, rewritten as

$$
\mathbf{F}(s)=\frac{1}{\mathbf{D}_{\mathbf{t}}(s)}[\mathbf{C A d j}(s \mathbf{I}-\mathbf{A}) \mathbf{B}]+\mathbf{E},
$$

with $\quad \mathbf{D}_{\mathbf{t}}(s)=|\mathbf{s} \mathbf{I}-\mathbf{A}|$ and $\operatorname{Adj}(\mathbf{s} \mathbf{I}-\mathbf{A})$ being the determinant and adjoint of matrix $(\mathbf{s} \mathbf{I}-\mathbf{A})$, respectively.

\section{A. PV installation model}

The model of the PV installation, i.e., the PV panel with the MPPT control and the DC bus (see Fig. 1), is presented in this Subsection.

The small-signal state-space model of the PV panel is derived from the I-V characteristics at the MPP ( $V_{m p p}$,

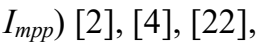

$$
\Delta i_{p v}=\Delta I_{p v s}-\frac{1}{R_{p v}} \Delta v_{p v}
$$

and the small-signal state-space model of the PV installation is

$$
\begin{aligned}
& \frac{d}{d t}\left[\Delta v_{p v}\right]=\left[\frac{-1}{C_{p} R_{p v}}\right]\left[\Delta v_{p v}\right]+\left[\begin{array}{ll}
\frac{-1}{C_{p}} & \frac{1}{C_{p}}
\end{array}\right]\left[\begin{array}{c}
\Delta i_{i} \\
\Delta i_{p v}
\end{array}\right]
\end{aligned}
$$

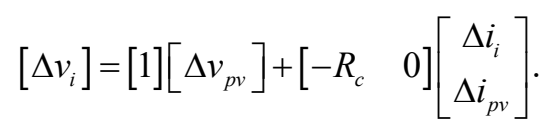

The MPPT control provides the PV panel reference voltage by fixing the maximum power delivered from the PV panel. According to the mathematical characterization of the MPPT control in [4], [22], the small-signal state-space model is expressed as

$$
\begin{aligned}
& \frac{d}{d t}\left[\Delta i_{p v s}\right]=[1]\left[\Delta v_{p v}\right] \\
& {\left[\Delta v_{p v r}\right]=\left[k_{i}^{m} k_{m}\right]\left[\Delta i_{p v s}\right]+\left[k_{p}^{m} k_{m}\right]\left[\Delta v_{p v}\right],}
\end{aligned}
$$

where $k_{p}{ }^{m}$ and $k_{i}{ }^{m}$ are the PI control proportional and integral gains of the MPPT control and $k_{m}=-2 I_{m p p} / V^{2}{ }_{m p p}$.

\section{B. PV panel voltage control and VSI model}

The model of the PV panel voltage control, VSI current control and grid-connected VSI in Fig. 1 is presented in this Subsection.

The grid $d$-reference current generated by the PV panel voltage control is expressed as the small-signal relation 


$$
\begin{aligned}
& i_{d r}=-\left(k_{p}^{p v}+\frac{k_{i}^{p v}}{s}\right)\left(v_{p v r}-v_{p v}\right) \Rightarrow \\
& \left\{\begin{array}{l}
s \Delta q_{p v}=\Delta v_{p v}-\Delta v_{p v r} \\
\Delta i_{d r}=k_{i}^{p v} \Delta q_{p v}+k_{p}^{p v}\left(v_{p v}-v_{p v r}\right)
\end{array}\right.
\end{aligned}
$$

where $k_{p}^{p v}$ and $k^{p v}{ }_{i}$ are the gains of the PV panel voltage control. According to (7), the small-signal state-space model of the PV panel voltage control is expressed as

$$
\begin{aligned}
& \frac{d}{d t}\left[\Delta q_{p v}\right]=\left[\begin{array}{ll}
1 & -1
\end{array}\right]\left[\begin{array}{c}
\Delta v_{p v} \\
\Delta v_{p v r}
\end{array}\right] \\
& {\left[\Delta i_{d r}\right]=\left[k_{i}^{p v}\right]\left[\begin{array}{l}
\Delta q_{p v}
\end{array}\right]+\left[\begin{array}{ll}
k_{p}^{p v} & -k_{p}^{p v}
\end{array}\right]\left[\begin{array}{l}
\Delta v_{p v} \\
\Delta v_{p v r}
\end{array}\right] .}
\end{aligned}
$$

Unity power factor of the VSI is considered, and the $q$ reference current $i_{q r}$ is zero.

The output $d$-reference voltage generated by the PI compensator of the $d q$-frame VSC current control is expressed as the small-signal relation

$$
\begin{aligned}
& u_{d}=\left(k_{p}^{c c}+\frac{k_{i}^{c c}}{s}\right)\left(i_{d r}-i_{d}\right) \Rightarrow \\
& \left\{\begin{array}{l}
s \Delta q_{c c}=\Delta i_{d r}-\Delta i_{d} \\
\Delta u_{d}=k_{p}^{c c}\left(\Delta i_{d r}-\Delta i_{d}\right)+k_{i}^{c c} \Delta q_{c c}
\end{array}\right.
\end{aligned}
$$

where $k^{c c}{ }_{p}$ and $k^{c c}{ }_{i}$ are the gains of the current control. According to (9), the small-signal state-space model of the AC grid $d$-reference voltage $u_{d}$ is

$$
\begin{aligned}
& \frac{d}{d t}\left[\Delta q_{c c}\right]=\left[\begin{array}{ll}
1 & -1
\end{array}\right]\left[\begin{array}{c}
\Delta i_{d r} \\
\Delta i_{d}
\end{array}\right] \\
& {\left[\Delta u_{d}\right]=\left[k_{i}^{c c}\right]\left[\Delta q_{c c}\right]+\left[\begin{array}{ll}
k_{p}^{c c} & -k_{p}^{c c}
\end{array}\right]\left[\begin{array}{c}
\Delta i_{d r} \\
\Delta i_{d}
\end{array}\right] .}
\end{aligned}
$$

Finally, the small-signal state-space model of the $d$-current dynamics is

$$
\begin{aligned}
& \frac{d}{d t}\left[\Delta i_{d}\right]=\left[\frac{1}{L_{f}}\right]\left[\Delta u_{d}\right] \\
& {\left[\Delta i_{d}\right]=[1]\left[\Delta i_{d}\right]+[0]\left[\Delta u_{d}\right],}
\end{aligned}
$$

where $L_{f}$ is the VSI filter inductance.

\section{B. qZSI model}

The derivation of the small-signal state space averaged model of the qZSI in Fig. 1 is discussed in this Subsection. The small-signal state-space averaged model of the qZSI power circuit is well documented in [1], [9], [10], [22], and it is not described for space reasons. This model relates the state vector $\Delta \mathbf{x}_{\mathbf{z}}=\left[\begin{array}{llll}\Delta i_{L 1} & \Delta i_{L 2} & \Delta v_{C 1} & \Delta v_{C 2}\end{array}\right]^{\mathrm{T}}$ with the inductor currents and capacitor voltages to the input $\Delta \mathbf{u}=\left[\Delta v_{i} \Delta i_{d c}\right.$ $\Delta d]^{\mathrm{T}}$ and output $\Delta \mathbf{y}=\left[\begin{array}{ll}\Delta i_{i} & \Delta v_{d c}\end{array}\right]^{\mathrm{T}}$ vectors with the qZSI input and output currents $i_{d c}$ and $i_{i}$, voltages $v_{i}$ and $v_{d c}$ and duty cycle $d$.

The small-signal state-space model of the duty cycle control is

$$
\begin{aligned}
& \frac{d}{d t}\left[\Delta q_{d c}\right]=\left[\begin{array}{lll}
0 & \frac{1}{1-D} & \frac{V_{d c, p}}{1-D}
\end{array}\right]\left[\begin{array}{c}
\Delta i_{L 2} \\
\Delta v_{C 1} \\
\Delta d
\end{array}\right] \\
& {\left[\Delta d_{r}\right]=\left[-k_{p}^{L} k_{i}^{d c}\right]\left[\Delta q_{d c}\right]} \\
& +\left[\begin{array}{ccc}
-k_{p}^{L} & -\frac{k_{p}^{L} k_{p}^{d c}}{1-D} & -\frac{k_{p}^{L} k_{p}^{d c}}{1-D} V_{d c, p}
\end{array}\right]\left[\begin{array}{c}
\Delta i_{L 2} \\
\Delta v_{C 1} \\
\Delta d
\end{array}\right],
\end{aligned}
$$

where $k^{d c}{ }_{p}$ and $k^{d c}{ }_{i}$ are the gains of the DC-link voltage PI-based control, $k_{p}^{L}$ is the proportional gain of the inductor- $L_{2}$ current P-based control and $D$ is the steadystate duty cycle.

At last, the small-signal state-space model of the LPF is represented by

$$
\frac{d}{d t}[\Delta d]=\left[-\omega_{c}\right][\Delta d]+\left[\omega_{c}\right]\left[\Delta d_{r}\right] .
$$

\section{Stability assessment of qZSI PV Power Systems}

Stability of qZSI PV power generation systems can be assessed from the real and imaginary part of the eigenvalues $\lambda_{A i}=\sigma_{A i} \pm j \omega_{A i}$ of the state-space matrix $\mathbf{A}$ in (1) calculated as $|\mathbf{A}-\lambda \mathbf{I}|=0$ : the real part $\sigma_{A i}$ represents the system damping and the imaginary part $\omega_{A i}$ represents the frequency of oscillations. The system is unstable if it contains any eigenvalue in the RHP (i.e., $\sigma_{A i}>0$ ) at the frequency mode $\omega_{A i}$. Stability of the qZSI PV power generation system can be compromised by the operating point because the state-space matrix $\mathbf{A}$ depends on it.

The poles of $\mathbf{F}(s)$ are the zeros of $\mathbf{D}_{\mathbf{t}}(s)$, namely the eigenvalues $\lambda_{A i}$ of the state space matrix $\mathbf{A}$ [13]. Therefore, system stability can also be assessed from the poles of $\mathbf{F}(s)$ (or zeros of $\mathbf{D}_{\mathbf{t}}(s)$ ). According to this, a frequency domain stability criterion based on the frequency characteristics of the state-space matrix determinant $\mathbf{D}_{\mathbf{t}}(s)$ is established for low damped oscillatory modes (i.e., for eigenvalues with $\left|\sigma_{A i}\right|<<\left|\omega_{A i}\right|$ ) in [13]. The criterion states that the zero-crossing frequency $\omega_{r}$ of the imaginary part of the state-space matrix determinant, $X_{D}(\omega)=\operatorname{Im}\left\{\mathbf{D}_{\mathbf{t}}(j \omega)\right\}$, is approximate to the frequency mode $\omega_{A i}$ and the stability of the system is determined by the product sign of the real part of the state-space matrix determinant, $R_{D}(\omega)=\operatorname{Re}\left\{\mathbf{D}_{\mathbf{t}}(j \omega)\right\}$, and the slope of the imaginary part $k_{x}(\omega)=\mathrm{d} X_{D}(\omega) / \mathrm{d} t$ at $\omega_{r}$ (i.e., $R_{D}\left(\omega_{r}\right) \cdot k_{x}\left(\omega_{r}\right)$ ); that is, a positive product means a stable mode, and vice versa. This frequency domain stability approach was used for power systems with highpenetration of grid-connected VSCs [13]. The present paper extends its application to PV power generation systems.

\section{Example}

A stability analysis of qZSI PV power generation systems (Fig. 1) is performed from the data in Table I. The PV panel delivers a $1 \mathrm{kV} 140 \mathrm{~kW}$ DC PV power system linked to a strong $0.4 \mathrm{kV}$ AC grid. The IGBT switching 


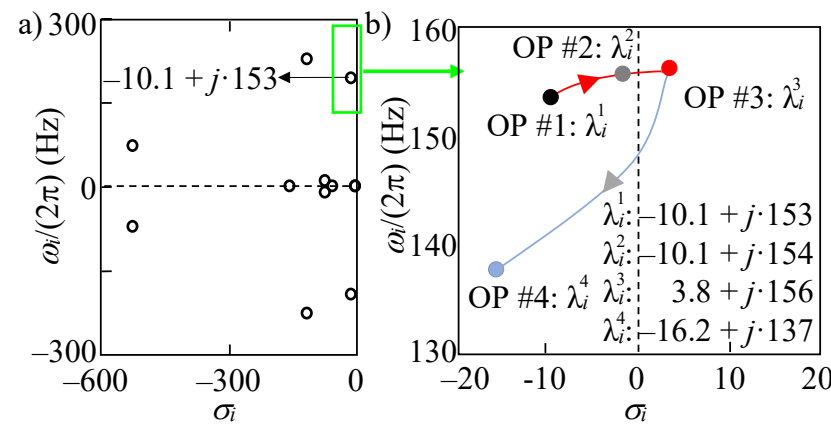

Fig. 2. Stability assessment by state space eigenvalue analysis: a) Eigenvalues of OP \#1. b) Trajectories of the eigenvalue related to instability.

frequency $f_{s w}$ is set at $10 \mathrm{kHz}$ as in [1]. Operating point influence on stability of the qZSI PV power generation system is investigated by state-space eigenvalue analysis, frequency domain characteristics of the state-space matrix determinant and PSCAD/EMTDC simulation. Four operating points are analysed:

Operating point \#1 (OP \#1): it is the stable operating point at steady-state with the active power $P$ delivered from DC to $\mathrm{AC}$ equal to $66 \mathrm{~kW}$ and the $\mathrm{DC}$ voltage $V_{d c}$ equal to $790 \mathrm{~V}$.

Operating point \#2 \& 3 (OP \#2 \& 3): influence of the active power delivered to the AC grid on stability is studied by increasing $P$ to $80 \mathrm{~kW}(\mathrm{OP} \mathrm{\# 2})$ and $94 \mathrm{~kW}$ (OP \#3) while keeping the DC voltage at $790 \mathrm{~V}$.

Operating point \#4 (OP \#4): influence of the DC peak voltage value on stability is studied by increasing $V_{d c}$ to $990 \mathrm{~V}$ while the active power delivered to the AC grid is equal to $94 \mathrm{~kW}$.

The eigenvalues $\lambda_{A i}=\sigma_{A i} \pm j \omega_{A i}$ in the four previous operating points are obtained from the state-space matrix A of the qZSI PV power generation system, and the terms $\sigma_{A i}$ and $\omega_{A i} /(2 \pi)$ are shown in Fig. 2 These eigenvalues verify system stability in the operating point \#1 and \#2 because they are not in the right half plane (RHP). As for the other operating points, it is worth noting that

- the increase in the active power delivered to the AC grid leads to system instability because the eigenvalue of the oscillatory frequency $f_{A i}=\omega_{A i} /(2 \pi)=156 \mathrm{~Hz}$ moves into the RHP (operating point \#3), and

- the increase in the DC peak voltage allows system stability to be obtained because the eigenvalue moves out of the RHP (operating point \#4). However,

Table I. - 140 kW 1 kV DC PV Power Generation System Data

\begin{tabular}{c|c|c}
\hline \hline & Parameters & Data \\
\hline PV installation & $R_{c}, C_{p}$ & $0.0667 \Omega, 10 \mathrm{mF}$ \\
\hline \multirow{2}{*}{$\begin{array}{c}\text { qZSI source } \\
\text { network }\end{array}$} & $L_{1}=L_{2}, r_{1}=r_{2}$ & $0.3 \mathrm{mH}, 0.011 \Omega$ \\
\cline { 2 - 3 } & $C_{1}=C_{2}, R_{1}=R_{2}$ & $3 \mathrm{mF}, 0.006 \Omega$ \\
\hline VSI & $R_{f}, L_{f}$ & $\approx 0 \Omega, 0.4 \mathrm{mH}$ \\
\hline MPPT control & $k^{m}{ }_{p}, k^{m}{ }_{i}$ & $0.01 \Omega, 0.5 \Omega / \mathrm{s}$ \\
\hline PV control & $k^{p v}{ }_{p}, k^{p v}{ }_{i}$ & $1.8 \Omega^{-1}, 75 \Omega^{-1} / \mathrm{s}$ \\
\hline CC control & $k^{c c}{ }_{p}, k^{c c}{ }_{i}$ & $0.424 \Omega^{-1}, 150 \Omega^{-1} / \mathrm{s}$ \\
\hline \multirow{3}{*}{ D control } & $V^{*}{ }_{d c, p}$ & $800 \mathrm{~V}$ \\
\cline { 2 - 3 } & $k^{d c}{ }_{p}, k^{d c}{ }_{i}$ & $0.016 \mathrm{~V}^{-1}, 125 \mathrm{~V}^{-1} / \mathrm{s}$ \\
\cline { 2 - 3 } & $k_{p}^{L}$ & $10^{-4} \mathrm{~A}^{-1}$ \\
\hline \hline
\end{tabular}

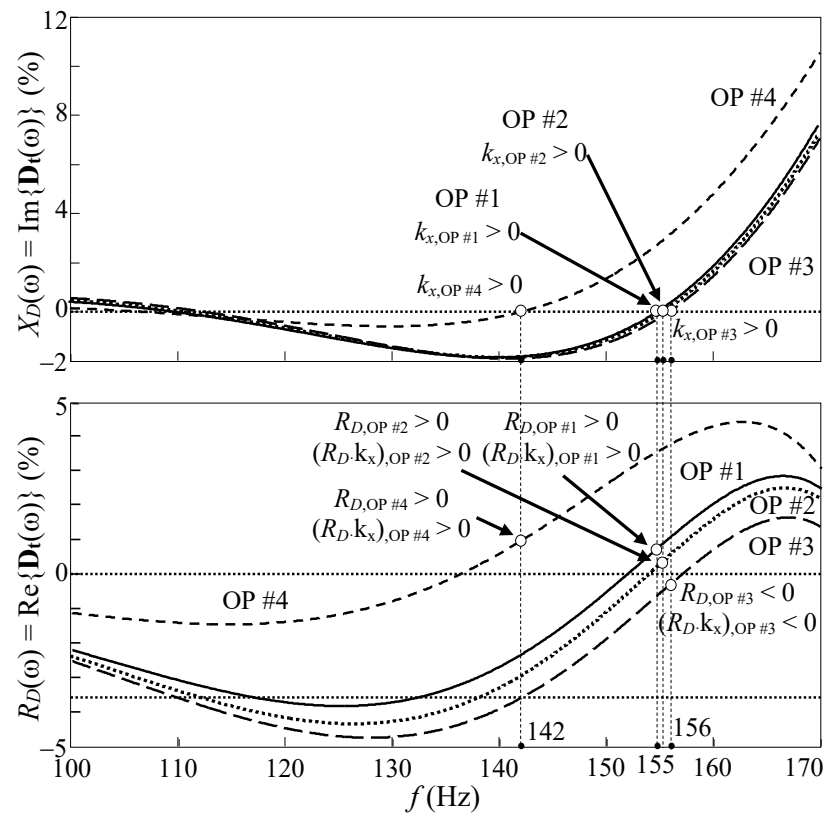

Fig. 3. Stability study using the state-space matrix determinant stability criterion.

increasing the DC peak voltage could lead to higher switch stress and lower voltage utilisation ratio.

The frequency domain stability criterion of the statespace matrix determinant in Fig. 3 and PSCAD/EMTDC simulations in Fig. 4 verify the above results.

It can be noted that the zero-crossing frequencies of the imaginary part curves $(155 \mathrm{~Hz}, 155.5 \mathrm{~Hz}$ and $156 \mathrm{~Hz}$ for OP \#1, OP \#2 and OP \#3) approximately match the oscillatory frequencies $\omega_{A i} /(2 \pi)$ of the eigenvalue in Fig. 2(b), the slope $k_{x}$ of the imaginary part curves at these frequencies is positive for all the operating points and the real parts $R_{D}$ at these frequencies are positive for OP \#1, OP \#2 and OP \#4 and negative for OP \#3. Thus,

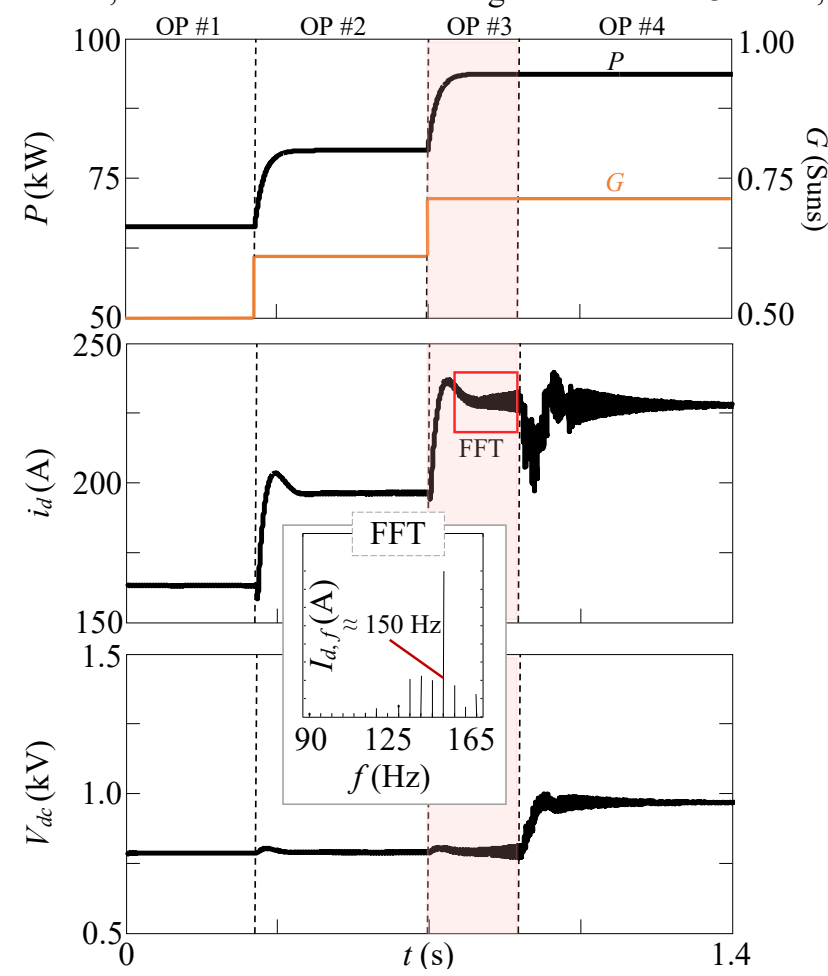

Fig. 4. Stability study by PSCAD/EMTDC simulations. 
the products of the slopes and the real parts $k_{x} \cdot R_{D}$ become positive for OP\#1, OP \#2 and OP \#4 and negative for OP \#3, indicating that the former are stable and the latter is unstable. It is worth noting that the stability criterion can be applied to assess stability of PV power systems by using their small-signal state-space averaged model since the model is a linearization of the PV power system.

In the PSCAD/EMTDC simulations, the PV panel increases the power from $P=66 \mathrm{~kW}$ (stable operating point \#1) to $P=80$ and $94 \mathrm{~kW}$ (operating point \#2 and \#3) but the qZSI PV power generation system becomes unstable at the operating point \#3. The frequency of unstable oscillations captured in the PSCAD/EMTDC simulations (i.e., $\approx 150 \mathrm{~Hz}$ ) approximately matches the oscillatory frequency of the eigenvalue $\omega_{A i} /(2 \pi)$. The increase of $V_{d c}$ from $790 \mathrm{~V}$ to $990 \mathrm{~V}$ (operating point \#4) returns the qZSI PV power generation system to stability after becoming unstable due to the increase of active power.

\section{Conclusion}

This paper presents a small-signal state-space averaged model of qZSI PV power generation systems and assesses stability of qZSI PV power generation systems by means of the frequency domain stability criterion of the statespace matrix determinant. This stability criterion is applied to the small-signal state-space averaged model of the system in the $s$-domain. The influence of the qZSI PV power generation system operating point on stability is studied. It is concluded that the increase of active power delivered to the AC grid can cause system instability whereas the increase of the DC voltage value reduces the impact of active power, but could also cause switch stress and bad voltage utilisation ratios. The previous results, validated by eigenvalue analysis and PSCAD/EMTDC simulation, contribute to the study of unsolved stability concerns in qZSI PV power generation systems. Further studies such as the use of the frequency-based model for stability assessment of grid-connected qZSI PV power generation systems could use the approach presented in the paper.

\section{Acknowledgement}

This work was supported in part by the Ministerio de Ciencia, Innovación y Universidades under Grant RTI2018-095720-B-C33.

\section{References}

[1] Y. Liu, H. Abu-Rub, B. Ge, F. Blaabjerg, O. Ellaban, P. Chiang, Impedance source power electronic converters, John Wiley and Sons, IEEE Press, Chichester, West Sussex, UK (2016).

[2] G. Walker, Evaluating MPPT converter topologies using a Matlab PV Model, Journal of Electrical and Electronics Engineering (2001). Vol. 21, no. 1, pp. 49-55.

[3] T. Degner, J. Schmid, P. Strauss, Distributed Generation with High Penetration of Renewable Energy Sources, Final Public Report of Dispower Project, 2006, ISBN 3-00-016584-3.

[4] M. Pokharel, A. Ghosh, C. N. Man Ho, Small-Signal Modelling and Design Validation of PV-Controllers With INC-
MPPT Using CHIL, IEEE Trans. Energy Conv. (2019). Vol. 34, no. 1, pp. 361-370.

[5] Y. Liu, B. Ge, H. Abu-Rub, F. Z. Peng, An effective control method for quasi-Z-source cascade multilevel inverter-based grid-tie single-phase photovoltaic power system, IEEE Trans. Ind. Informatics (2014). Vol. 10, no. 1, pp. 399-407.

[6] O. Husev, F. Blaabjerg, C. Roncero-Clemente, E. RomeroCadaval, D. Vinnikov, Y. Siwatoki, R. Strzelecki, "Comparison of impedance-source networks for two and multilevel buckboost inverter applications", IEEE Transactions on Power Electronics (2016). Vol. 31, no. 11, pp. 7564-7579.

[7] Y. P. Siwakoti, F. Z. Peng, F. Blaabjerg, P. C. Loh, G. E. Town, "Impedance-source networks for electric power conversion. Part I: A topological review", IEEE Transactions on Power Electronics (2015). Vol. 30, no. 2, pp. 699-716.

[8] Y. P. Siwakoti, F. Z. Peng, F. Blaabjerg, P. C. Loh, G. E. Town, S. Yang, "Impedance-source networks for electric power conversion. Part II: Review of control and modulation techniques", IEEE Transactions on Power Electronics (2015). Vol. 30, no. 4, pp. 1887-1906.

[9] J. Liu, J. Hu, L. Xu, Dynamic modeling and analysis of Z-source converter-derivation of AC small signal model and design-oriented analysis, IEEE Trans. Power Electron. (2007). Vol. 22, no.5, pp. 1786-1796

[10] Y. Liu, B, Ge, F. J. T. E. Ferreira, A. de Almeida, H. AbuRub, Modeling and SVPWM control of quasi-Z-source inverter, Proc. 11th International Conference on Electrical Power Quality and Utilisation (EPQU), Lisbon, Portugal, 2011, 1-7.

[11] C. Roncero-Clemente, E. Romero-Cadaval, O. Husev, D. Vinnikov, S. Stepenko, Simulation of Grid Connected ThreeLevel Neutral-Point-Clamped qZS Inverter using PSCAD, Electrical, Control and Communication Engineering (2013). Vol. 2, pp. 14-20 (10.2478/ecce-2013-0002).

[12] O. Husev, C. Roncero-Clemente, S. Stepenko, D. Vinnikov, E. Romero-Cadaval, CCM operation analysis of the single-phase three-level quasi-Z-source inverter, 15th International Power Electronics and Motion Control Conference (EPE/PEMC), Novi Sad, 2012, pp. DS1b.21-1-DS1b.21-6.

[13] H. Liu, X. Xie, W. Liu, "An oscillatory stability criterion based on the unified dq-frame impedance network model for power systems with high-penetration renewables", IEEE Trans. on Power Systems (2018). Vol. 33, no. 3, pp. 3472-3485.

[14] Y. Tan, D. Kirschen, N. Jenkins, A model of PV generation suitable for stability analysis, IEEE Trans. on Energy Conversion (2004), Vol. 19, no. 4, pp. 748-755.

[15] Y. Xue, M. Manjrekar, C. Lin, M. Tamayo, J. Jiang, Voltage stability and sensitivity analysis of grid-connected photovoltaic systems, Proc. IEEE PES Gen. Meet., Detroit, MI, USA, Jul. 2011, pp. 1-7.

[16] V. Castiglia, R. Miceli, F. Blaabjerg, Y. Yang, SmallSignal Modeling and Experimental Validation of the Threephase Quasi-Z-Source Inverter, 2020 IEEE 21st Workshop on Control and Modeling for Power Electronics (COMPEL), Aalborg, Denmark, 2020, pp. 1-8.

[17] Z. Liang, S. Hu, H. Yang, X. He, "Synthesis and design of the AC current controller and impedance network for the quasiZ-source converter", IEEE Transactions on Industrial Electronics (2018). Vol. 65, no. 10, pp. 8287-8296.

[18] S. Stepenko, O. Husev, D. Vinnikov, C. RonceroClemente, S. Pires Pimentel, E. Santasheva, Experimental Comparison of Two-Level Full-SiC and Three-Level Si-SiC Quasi-Z-Source Inverters for PV Applications. Energies (2019). Vol. 12, 2509.

[19] W. Liu, Y. Yang, T. Kerekes, E. Liivik F. Blaabjerg, Impedance Network Impact on the Controller Design of the QZSI for PV Applications, 2020 IEEE 21st Workshop on Control and Modeling for Power Electronics (COMPEL), Aalborg, Denmark, 2020, pp. 1-6.

[20] L. Oliveira-Assis, E. P. P. Soares-Ramos, R. Sarrias-Mena, P. García-Triviño L. M. Fernández-Ramírez, Large-Scale Grid 
Connected Quasi-Z-Source Inverter-Based PV Power Plant, 2020

IEEE International Conference on Environment and Electrical Engineering and 2020 IEEE Industrial and Commercial Power Systems Europe (EEEIC / I\&CPS Europe), Madrid, Spain, 2020, pp. 1-6.

[21] O. Husev, D. Vinnikov, C. Roncero-Clemente, E. Chub, E. Romero-Cadaval, Single-Phase String Solar qZS-based Inverter: Example of Multi-Objective Optimization Design, IEEE Transactions on Industry Applications (2020). doi: 10.1109/TIA.2020.3034292.

[22] Ll. Monjo, L. Sainz, J. J. Mesas, J. Pedra, “Quasi-Z-source inverter-based photovoltaic power system modeling for grid stability studies", Energies (2021). Vol. 14, no. 508, pp. 1-16. 